\title{
The IMPACT OF ChILDHOOd HeALTH ANd Cognition on Portfolio Choice
}

Dimitris Christelis, Loretti Dobrescu, Alberto Motta 


\title{
5 The Impact of Childhood Health and Cognition on Portfolio Choice
}

\author{
Dimitris Christelis, Loretti Dobrescu and Alberto Motta
}

\subsection{Why childhood conditions can affect risk taking in older age}

Childhood health is by now recognized to influence future educational and economic outcomes. Children who experience poorer childhood health have significantly lower educational attainment, poorer health, and lower socioeconomic status as adults (Case, Fertig and Paxson, 2005; Currie, 2009). For example, Case and Paxson (2008) investigated the relationship between height (as indicator for early health and socio-economic status), cognitive functions and health status at older ages and found that taller individuals (considered to be healthier and wealthier during childhood) have greater cognitive skills on average, report significantly fewer difficulties with activities of daily living, and are in considerably better physical and mental health.

Furthermore, cognitive skills in childhood have their own implications for adulthood. Bad test scores (which could indicate worse cognitive skills) are associated with lower socioeconomic status in childhood, and gaps in abilities by socioeconomic status open up early and tend to persist later in life (Heckman, Stixrud, and Urzua, 2006). As captured by achievement test scores measured during education in childhood and adolescence, early cognition is, together with educational attainment, an important determinant of adult socioeconomic success.

Among the many outcomes in adulthood that can be influenced by childhood health and cognition, we will focus on portfolio choice and risk attitudes in the older segment of the population. This analysis is particularly relevant in light of the financial decisions that older individuals face nowadays. Recent reforms of social security systems around the world have been putting individuals more and more in charge of their own financial security after retirement, while the supply of complex financial products has increased. As a consequence, portfolio selfmanagement is becoming commonplace.

Recent literature on the relation between portfolio choice and health (Rosen and $\mathrm{Wu}, 2004$ ) has found that households in poor health tend to hold safer financial portfolios, even after controlling for several other predictors of portfolio choice. In addition, poor health status is associated not only with safer portfolios but also with less diversified ones. The reason is that health shocks in retirement can alter one's financial circumstances and planning horizon, with a direct impact on household economic decisions. When thinking about the relationship between 
childhood and adult health previously discussed, it might thus well be that adult health is partly mediated by childhood health. We also know that cognition in older age is positively associated with risky portfolio choice (Christelis, Jappelli and Padula, 2010), and thus, in the same vein, it could also be partly mediated by childhood cognition.

In order to better understand the relationship between childhood health and cognition and risky portfolio choice later in life, we will use the SHARELIFE dataset that provides rich information on childhood health and cognition, and the subsequent financial history of the older population in fifteen European countries, using a harmonized questionnaire that makes results comparable across countries.

\subsection{Indicators of Childhood Health and Cognition}

The SHARELIFE questionnaire has a rich set of questions pertaining to health during childhood that elicits information on access to care, adverse health events, severe illnesses, vaccinations, hospitalizations, as well as a question on selfreported health during childhood. For our analysis we use, first, the question on whether respondents had access to a usual source of care, that is to a particular person or a place that they went to when they were sick or needed advice about their health. A negative answer to this question could indicate that respondents did not get either the necessary treatment when they became sick or preventive advice needed to forestall health problems in the future. In addition, this lack of medical help could have made them feel more insecure and thus more cautious, which in turn could have shaped their attitude to risk later in life.

Obviously, access to medical care is an important target of welfare and social policies, and a lasting impact of its unavailability in childhood would make such a target even more important to achieve.

The prevalence of the availability of a usual source of care during childhood is shown in the first column for each country in Figure 5.1, and we note that while it is above $95 \%$ for most countries, it is lowest for Greece (83\%), the Czech Republic $(87 \%)$, and Germany $(90 \%)$.

Figure 5.1: Prevalence of childhood health and cognition variables 


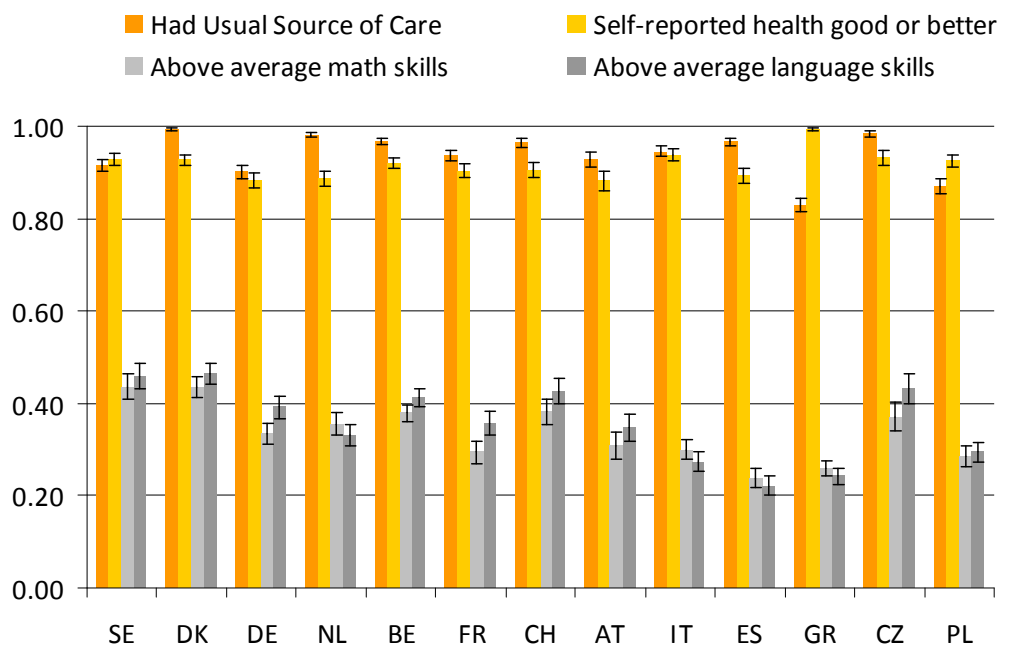

Source: SHARELIFE. The number of observations differs slightly by variable, but it is on average approximately equal to 27,650 .

The second indicator of childhood health that we consider is the subjective health status during childhood as reported by respondents today. This question should provide a broad overview of health status and give an indication of the actual extent of the health problems faced that is not captured by objective measures (e.g. days spent in a hospital). On the other hand, answers to this question could be affected by differences in reporting style across individuals and countries (Jürges, 2007). SHARELIFE respondents could rate their health as excellent, very good, good, fair and poor, and we construct an indicator for the highest three answers, the distribution of which is shown across countries in the respective second columns in Figure 5.1. Prevalence ranges from 88\% to 94\%, with Austria and Germany being at the lower end of the range, and Italy and the Czech Republic at the high one. The one exception is Greece, in which less than $1 \%$ or respondents declare being in fair or poor health during childhood.

Turning now to cognition in early life, we use the answers to two questions that inquire about the respondents' relative position to their peers in school with respect to mathematics and language skills. To this purpose, we construct two indicators for having above average skills. The distribution of those two indicators is shown in the third and fourth country columns in Figure 5.1, and we note that the range goes from roughly 22\% to $45 \%$ for both indicators, with Greece and Spain exhibiting the lowest prevalence of above average skills and Sweden and Denmark the highest. As is the case with the self-reported health question, answers to the two childhood cognition questions could be affected by differences in respondents' reporting styles. 


\subsection{Asset Ownership and Risk Preferences}

We now examine the effect of childhood health and cognition on portfolio choice and risk taking in older age. We will concentrate our discussion on four economic choices, namely whether one has ever owned stocks, mutual funds or a private business (this information can be found in SHARELIFE), and whether one is willing to take any financial risks (the latter information is provided in the second wave of SHARE). All three investment choices entail risk taking, and make demands on the cognitive skills of their owners. Furthermore, the assumption of financial risk depends on other sources of risks the investor faces, including health risk. It also depends on the amount of information the investor has on the properties of the different assets, and this in turn is affected by the cognitive skills that the investor has, which were partly formed during childhood.

For each economic choice/health (or cognition) variable combination, we use a probit model in order to associate the choice to the health or cognition variable of interest. We include country fixed effects in order to account for specific conditions prevailing in each country, and we also interact the health or cognition variable with the country dummies in order to allow as much as possible for differential effects across countries. Our variable specification also includes the respondents' gender, education and marital status, and, crucially, indicators of the respondents' socioeconomic status during childhood. This is achieved by including in our model variables denoting the number of rooms in the house where respondents lived (adjusted for family size), and the number of books that the respondents' family possessed. As a result, any effects of the childhood health or cognition variables that we find will be net of all the aforementioned factors, and thus less likely to be spurious.

Before discussing our results, it is worth noting that our sample could suffer from survivor bias, i.e. we might predominantly have people in our sample that were physically and cognitively in good shape during childhood, which in turn led to a longer life. To the extent that this is true, the range of values of the health and cognition variables could be somewhat limited and skewed to the higher end of the distribution, and this lack of variation could weaken our empirical results.

The results for stock ownership are shown in Figure 5.2. We find that the existence of a source of care during childhood is positively associated with stock ownership by roughly 16 percentage points (pp) in Switzerland, $8 \mathrm{pp}$ in Austria, and 5 pp in Italy. Good or better self-reported health matters only in Sweden (9 pp). On the other hand superior mathematics skills boost stock ownership in all countries in our sample except Denmark by roughly 2 to $11 \mathrm{pp}$, while language skills show a slightly weaker but still very relevant positive association that ranges from 2 to 12 pp everywhere but Sweden, Denmark, Germany, and Austria. These results are consistent with previous findings that point out the considerable effect of cognitive skills on stockholding. 
Figure 5.2: Coefficients (marginal effects) on likelihood of having ever owned stocks

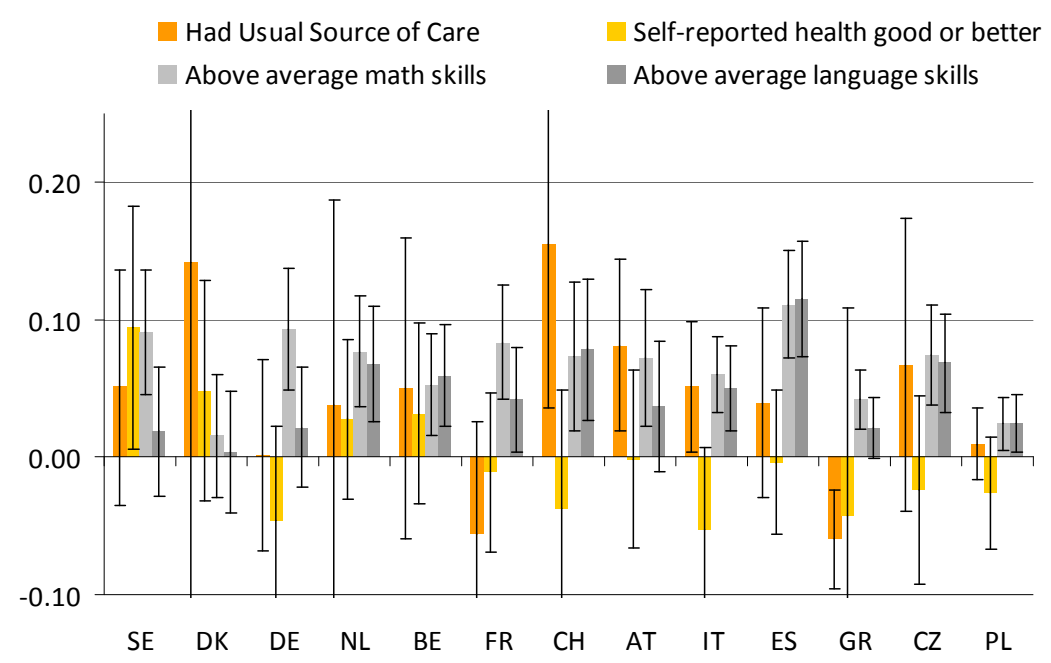

Source: SHARELIFE. The number of observations is approximately equal to 24,850 on average, depending on the specification.

We now turn to investment in mutual funds, shown in Figure 5.3. We find that having a usual source of care has a strong positive association with such an investment in Switzerland, Austria, Italy, and the Czech Republic, with magnitudes ranging from 7 to $23 \mathrm{pp}$. On the other hand, good health does not seem to matter anywhere. Above average mathematics skills are once more pretty strong for all countries except Austria and the Czech Republic, with the associations ranging from roughly 2 to $10 \mathrm{pp}$. Language skills seem to also play an important role for mutual fund investment in the Netherlands, Belgium, France, Italy, Spain, Greece and Poland. We note that the associations for mutual funds are slightly weaker than those for stocks, which is consistent with the fact that the latter are more demanding than the former in terms of performance monitoring and evaluation.

Figure 5.3: Coefficients (marginal effects) on likelihood of having ever owned mutual funds 


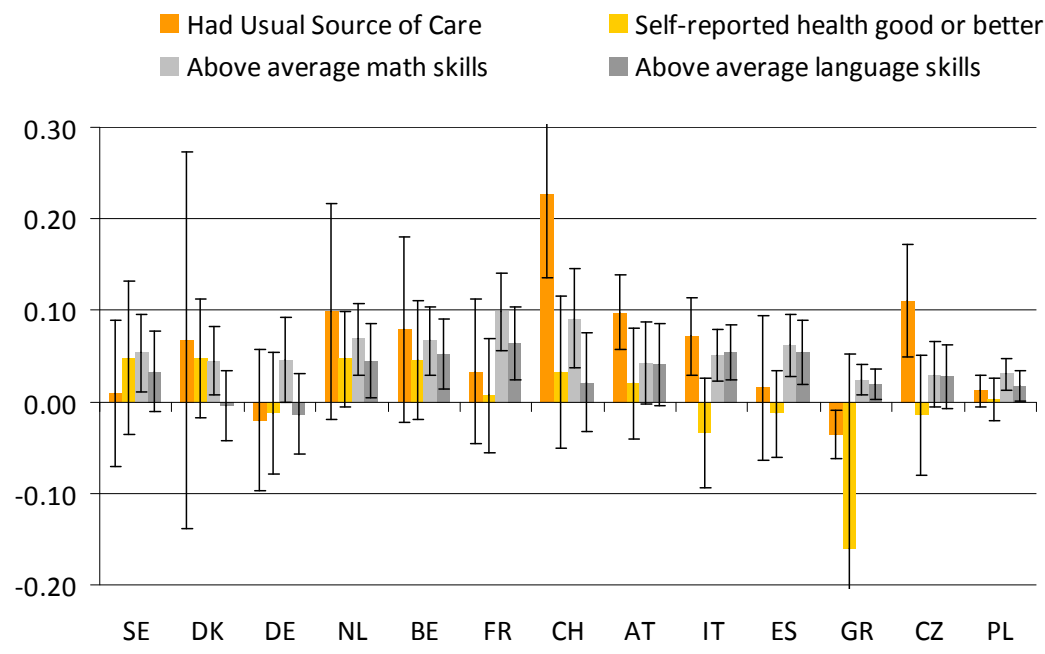

Source: SHARELIFE. The number of observations is approximately equal to 24,850 on average, depending on the specification.

The ownership of a business is to a large extent affected by intangibles like ambition, entrepreneurial spirit, and perseverance, and thus might be less affected by adverse health and cognition status than the previous two assets. Furthermore, circumstances might be such that owning a business is essentially the only career path available (e.g. in agriculture, or when one is shut out from civil service due to discrimination), which means that it does not involve as much risk taking as normally assumed. Perhaps because of these considerations, we find (results are shown in Figure 5.4) a sizeable positive association with the availability of a usual source of care only in France ( $3 \mathrm{pp}$ ), but we should note that there are no business owners that had fair or poor childhood health in Denmark, the Netherlands and Switzerland, and this lack of sample variability makes estimation for these three countries impossible. Similarly, we find no significant effects of good selfreported health (there are no business owners that had bad childhood health in Greece). Above average cognitive skills are now much weaker than in the case of stocks and mutual funds, with mathematics skills still mattering, however, in Italy (2 pp), Spain (3 pp) and the Czech Republic (1 pp), while language skills don't seem to play any role in ever owning a business.

Figure 5.4: Coefficients (marginal effects) on likelihood of having ever owned a business 


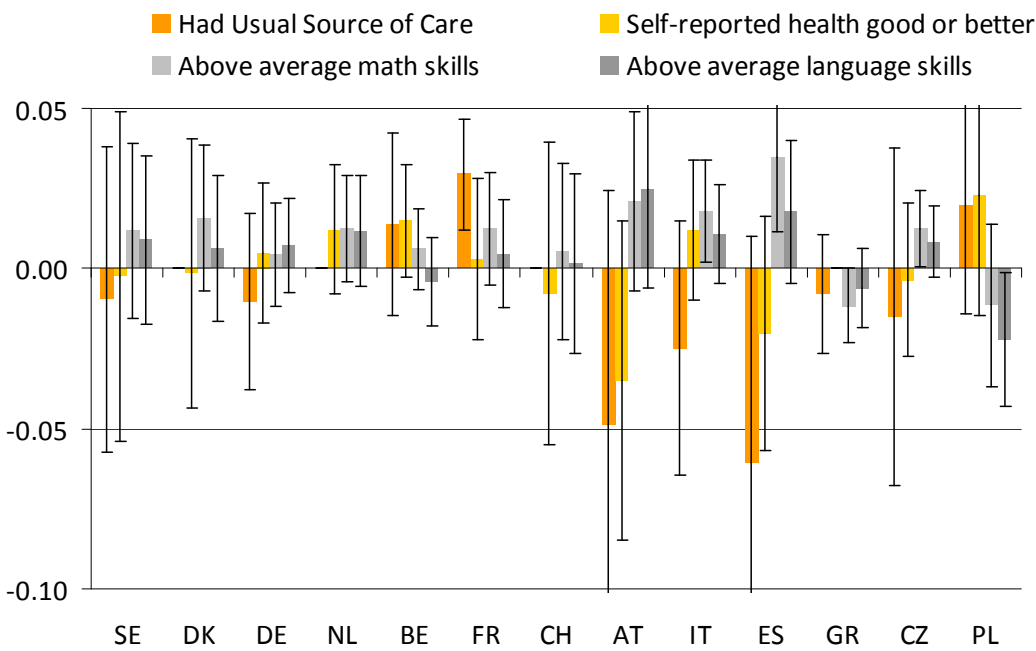

Source: SHARELIFE. The number of observations is approximately equal to 24,850 on average, depending on the specification.

We would expect that the health risk should negatively affect financial risk taking, as individuals subject to the former might want to control overall risk in their lives by limiting the latter. To that effect, we find (results are shown in Figure 5.5 taking in the Netherlands ( $20 \mathrm{pp}$ ), and Italy ( $7 \mathrm{pp}$ ). On the other hand, the association with self-reported health is not significant anywhere. In addition, we find that above average mathematics skills are strongly positively associated with financial risk taking in Germany, the Netherlands, Belgium, Italy and Greece (magnitudes range from 4 to $8 \mathrm{pp}$ ). The importance of language skills is slightly less widespread, but the associations are still relevant in the Belgium (7 pp), France (6 pp), and the Czech Republic (5 pp).

Figure 5.5: Coefficients (marginal effects) on likelihood of willing to assume some financial risk 


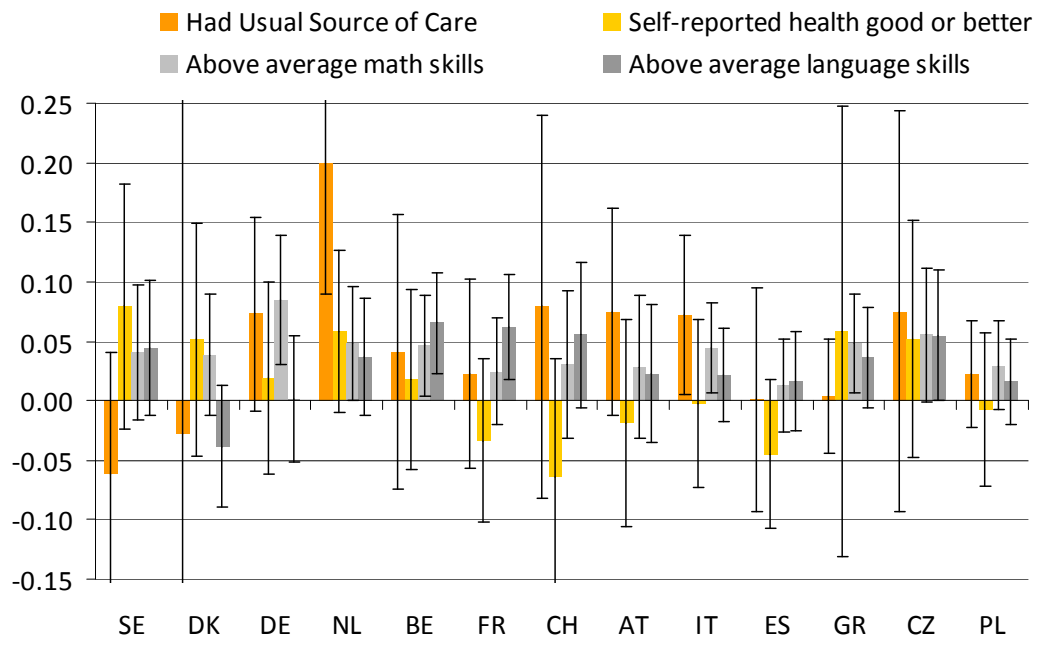

Source: SHARELIFE and SHARE wave 2. The number of observations is approximately equal to 16,400 on average, depending on the specification.

\subsection{Summary}

Childhood health and cognition have lasting effects on health, cognition and socioeconomic status later in life, and thus directly or indirectly a number of economic choices and attitudes.

Lack of a usual source of care is associated with less investment in stocks, mutual funds, while the association with private business ownership and risk taking is quite weaker. The effects of poor childhood health as reported by respondents are weaker and less widespread.

Childhood cognition, as represented by above average mathematics and language skills, is strongly positively associated with investment in stocks and mutual funds, and less so with ownership of a private business. The positive association is also strong with financial risk taking.

Our results point to the necessity and economic benefits of welfare policy interventions early in life that aim to increase access to health care providers. Such interventions should also aim to make health care more affordable, and to include initiatives for disease prevention and education on health issues. Furthermore, as our results are not geographically concentrated in any particular area of the European Union, the scope for such interventions seems to be pretty wide.

Given that we find strong evidence that childhood cognition has a lasting impact in many economic outcomes in older age, the potential benefits of interventions aiming at boosting childhood cognitive skills are very high. Such interventions could include more resources for high quality childcare, for remedial 
education of students that lag behind their peers, for programs that aim to prevent early school leaving, and for post-secondary education training. The cost of such resources should be amply justified by the substantial societal benefits of widespread higher childhood cognitive skills, namely higher human capital formation, decreased income and wealth inequality in adulthood, and an associated increase in social cohesion.

\section{References}

Case A., Fertig A., Paxson C. (2005). The lasting impact of childhood health and circumstance. Journal of Health Economics, Vol. 24(2), pp. 365-389.

Case A., Paxson C. (2008). Height, health and cognitive function at older ages. American Economic Review Papers and Proceedings, Vol. 98(2), pp. 463-467.

Christelis D., Jappelli T., Padula M. (2010). Cognitive abitilies and portfolio choice. European Economic Review, Vol. 54(1), pp. 18-38.

Currie J. (2009). Healthy, wealthy, and wise: socioeconomic status, poor health in childhood, and human capital development. Journal of Economic Literature, Vol. 47(1), pp. 87-122.

Heckman J.J., Stixrud J., Urzua S. (2006). The effects of cognitive and noncognitive abilities on labor market outcomes and social behavior. Journal of Labor Economics, Vol. 24(3), pp. $411-482$.

Jürges, H. (2007). True health vs. response styles: exploring cross-country differences in selfreported health. Health Economics, Vol. 16(2), pp. 163-178.

Rosen H., Wu S. (2004). Portfolio choice and health status. Journal of Financial Economics, Vol. 72(3), pp. 457-484. 